\title{
The Influence of Internet Search on College Students Independent Thinking Against the Background of Big Data
}

\author{
Mengting $\mathrm{Zhu}^{1, *}$ Xiaodie Dong ${ }^{1}$ \\ ${ }^{1}$ Business Institution, Hohai University, Changzhou, Jiangsu 213022, China \\ *Corresponding author. Email: dnydtszmt@163.com
}

\begin{abstract}
Against the background of big data, the convenience of Internet search expands the knowledge of college students, and stimulates the activity and creativity of thinking to some extent. However, overreliance on search engine will weaken the independent thinking ability of college students. Starting from the current situation of college students using the Internet, this paper discusses the mechanism of the influence of Internet search on college students' independent thinking, and then puts forward how college students use Internet search properly in the context of big data, and maintain their independence of thinking.
\end{abstract}

\section{Keywords: independent thinking, college students, Internet searching}

\section{INTRODUCTION}

With the broad application of computer and Internet, various data infiltrates into human's all aspects of life with a surprising speed, including learning. It shows exponential growth, and data explosion will bring human into the era of "big data". In October 2019, the Ministry of Education issued "Opinions on deepening the Reform of undergraduate Education and Teaching in an All-round way to improve the quality of talent training " which proposed to improve the proportion of time for students to control their study independently, and to enhance students' innovative ability and consciousness. As learner, college students should pay more attention to cultivating self-learning independence and learning ability than other students. On the one hand, under the background of "big data", using Internet search can broad the ways of thinking for college students, and they can grasp the question from different dimensions. On the other hand, it's unfavorable for college students to get standard answers without independent thinking which will increase their learning dependence and blind obedience to Internet, which is bad for innovation cultivation. This study will explore the correct way for college students when using Internet search and discuss how to maintain the independence of thinking in the era of "big data".

\section{LITERATURE REFERENCES}

At present, the Chinese and foreign literature on the study of college students' thinking mode under the network environment is mainly based on whether the network environment is helpful to cultivate the independent critical thinking of college students. For this, different scholars hold different ideas, and we categorize them into three parts.

First, the network learning environment is conducive to enhancing the critical thinking, creativity and the ability to reflect for college students. Hu Yang[1] analyzed the characteristics of network communication and thought that network communication makes students' thinking mode develop towards global perspective, subject spirit, new consciousness and free creation. Chun Meiwu[2] did a 16-week experiment about the application of web in teaching, she found that the web-based model can not only help the learners perform better but also enhance their autonomy and independent thinking in learning, and so is their learning interest.

Second, the learning style under the network situation is not conducive to the formation of independent thinking and deep critical thinking of college students. Wang Tingting, Yi Mengchun and Chen Xin[3] concluded that the use of shallow critical thinking of students in Xiamen University was more than that of deep critical thinking through a questionnaire survey of 350 college students. Shi Huihua[4] discussed the situation that students are prone to rely on Internet search too much based on the thinking of students majoring in social science, and she thought teaching concepts and ways of teaching should make innovations in such a network environment. Third, the network learning environment not only strengthens the reflection to the student's own idea, the 
ability of searching, but also has the negative influence to students' way of thinking. Hou Dongcheng and $\mathrm{Xu}$ Jianwen [5] believe that in the network environment, there are a large number of references for college students' thinking activities, and their strong curiosity makes them gradually strengthen their critical thinking, but the extreme of information sharing can easily lead to absolutization of thinking mode and weaken the thinking subjectivity of college students. Huangshan Ya and Chen Lei[6] study that the network intelligent learning environment is conducive to the cultivation of college students' thinking ability and the development of higher-order thinking ability, but the intuitive perception of online information can easily form the students' inertia of thinking, and their ability of imagination and logical thinking is gradually declining.

The above literatures discuss the influence of network search on college students' independent critical thinking under the background of big data from different aspects. With the advancement of time, researchers believe that Internet search is prone to hurt the cultivation of college students' ability to logical thinking and autonomous learning. However, there are lack of the discussion on correct way of Internet search and the mechanism how Internet search influence students' independent thinking. Based on the current research foundation, this paper makes a deep analysis on how college students can maintain their thinking independence, correctly use the network as a learning tool and how Internet search affects students' independent thinking. We put forward corresponding suggestions as final.

\section{CURRENT SITUATION OF INTERNET SEARCH}

On the one hand, the fundamental characteristic of "virtual" is to point the impossibility of reality, or point to the possibility of impossibility. The virtuality of the Internet breaks the boundary between truth and falsehood, breaks the boundary between traditional possibility and reality. It expands the new understanding of possibility and improves the thinking ability of college students[7].

On the other hand, college students' conceptions of world, value and life are not fully mature, they are easy to follow others. To some extent, the popularity of network has encouraged the thinking inertia of college students. With the development of network technology, the answers of many questions can be quickly obtained through search, which makes college students ignore the importance of autonomous thinking and gradually rely on the convenience of search engines. In addition, under the background of big data, a broad application of smart phones and information technology in the network makes knowledge fragmentation, even like "fast food". Since the convenience of time, place, network technology and intelligent equipment, college students choose "fast food reading", which is not helpful to think deeply. Consequently, thinking is impetuous and superficial. The knowledge and experience obtained from network is mostly an established system, not summarized through students' own practice. Losing the process of acquiring knowledge step by step, college students always fail to understand the information deeply, so they just grasp massive information by accumulation simply.

Further explore the major distribution of college students' using the Internet for learning search. We distributed 203 questionnaires, got full 195 back, the effective rate of the questionnaire was $96.06 \%$. We definite "not use network for searching answers" as frequency 0 , "use network for searching answers in whole process" as frequency 1 . We believe that 0.15 is a reasonable demarcation point: it is helpful to understand the question more comprehensively, to come up with more ideas when using network for project or homework properly. According to the results of the questionnaire, the distribution of students' majors that use the Internet to search answers more than frequency 15 percent during the completion of project or homework as follows ("Fig. 1"):

\section{proportion}

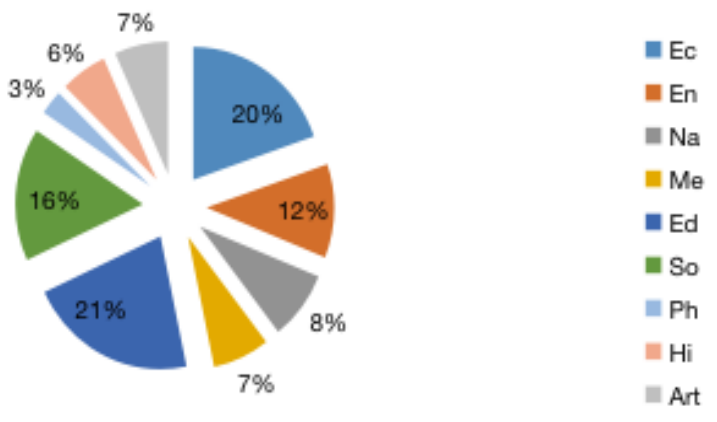

Fig. 1. Majors using network search exceed 0.15 . 
We can know that students majoring in education, economics, management, sociology and the like use network search for lesson study to a large extent, followed by engineering, science, medicine and other majors. Students majored in philosophy, history, art show to be more independent when completing homework or project task. There are two reasons for this phenomenon. Firstly, the major distribution of interviewees is different. The proportion of students majored in education, management, medical and so on is higher, while the students majored in philosophy, history and art are fewer. Secondly, the nature of the subjects is different. The latter majors are not so focused on the unity of the answer compared to former majors, like philosophy emphasizes more on selfunderstanding. Some courses of history and art stress more on practice rather than textbook homework.

\section{THE INFLUENCE MECHANISM OF INTERNET SEARCH ON COLLEGE STUDENTS INDEPENDENT THINKING}

The basic level of independent thinking is to solve problems autonomously. When in doubt, we should first analyze what the problem is, what we know about the problem, then plan the solution, implement the solution, and finally reflect on the evaluation. But the convenient Internet often makes college students choose to skip the basic analysis of the problem and use search engines to find the answer. The questions are condensed into short keywords, which are then cursorily filtered through the database to yield a wealth of relevant information. Traditional learning mode of thinking gradually turns into the computer mode of thinking. With the speed and determination of the computer, students tend to throw away the original careful thinking[8]. On the surface, college students improve study efficiency, but the solution of the problem needs the integration and transformation of the brain. The network information makes them gradually equate the retrieval results with the end of thinking. Furthermore, the redundant information in the network database will cause the appearance of cognitive overload. The redundant information that occupies the limited cognitive resources couples with the university students' anxious mentality, resulting in the misunderstanding of potential valuable information. As a result, driven by both subjective and objective factors, the Internet may weaken the ability of college students to think independently.

The main body of thinking is human, the network and information are usually our tools and hands to help understanding the physical world. However, in certain cases, they can also become the direct character of thought, even part of the object of thought. With the increasing dependence of subject on network and information, under certain conditions, they can become the substitute of thinking subject - man, that is, a thinking subject other than man[9]. The emergence of the so-called specific conditions, in fact, is concession of people as main body of thinking. This induces the network originally serve us to become the host of thinking. The independence of the mind depends on human beings, not on sophisticated machines.

With the deepening of thinking independence, it will develop from the independent stage into the innovation stage. Against the background of big data, college students gradually learn to use modern thinking media and thinking tools to carry out thinking activities. Openness is the source of innovation. Because of the open nature of the Internet, it provides college students with the opportunity and ability to make a variety of choices as well as a large amount of information, thus stimulating their imagination, creativity and subjective initiative, improve the creative thinking ability of them. What's more, the network enables the university student to surmount the fetter of campus and the Book Knowledge, encourages the student to make full use of wisdom, displays the imagination, creates the natural world originally does not exist the new realm, the new world[10]. The college students' independent thinking should not be closed-minded and individualistic "The rain the sound of the wind, the sound of the object; family affairs and the world, concerned about everything.", individual creative thinking must integrate with contemporary society's core values. The network connects the individualized creative thinking of countless college students, promotes the collision and friction of thinking, and finally realizes the integration of individualized and socialized thinking ("Fig. 2").

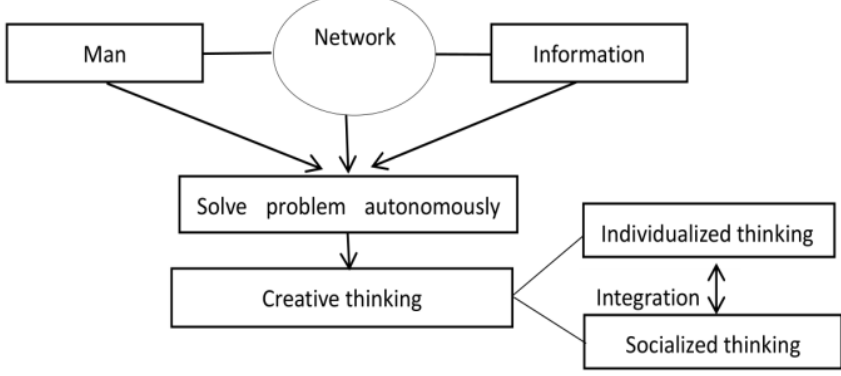

Fig. 2. The influence mechanism of Internet search on college students independent thinking. 


\section{CONCLUSION}

Against the background of big data, the Internet search provides a lot of information for college students, arouses the subject's imagination, and is beneficial to the production of creative thinking to some extent. However, the convenience of the Internet also encourages mental inertia, making college students rely on the convenience of searching for answers, skipping the critical process of independent thinking. In fact, using does not mean relying on, college students could have avoided the "make the host and the guest exchange roles" situation by using the brain to analyze the basic elements of the problem before gradually searching through the Internet, to discover the conflict between different information, information and individual cognitive environment. The individual's ideas and stereotypes are always in harmony with each other, so the consciousness cannot tolerate the contradiction between the cognitive elements and tries to eliminate the disharmony between them[4]. And this is the embodiment of independent thinking.

The correct use of network resources in the learning process, first of all, students need to do in-depth thinking of textbook knowledge, do more reading related course books to form their own understanding, viewing the network as a learning resources rather than a reference answer library. Secondly, teachers should create new topics, strict assessment. When assigning class discussion and homework, the actual situation of students must be taken into consideration. To encourage students think independently, colleges should treat online plagiarism seriously. Third, the college in the curriculum can increase the proportion of applied courses, strengthening the practice of teaching and promoting college students form their own opinions in light of the actual situation.

\section{References}

[1] $\mathrm{Hu}$ Yang. Changes and Countermeasures of the Network's Way of Thinking for College Students [J]. Journal of Hunan Vocational and Technical College of Mass Media, 2003(6):53.

[2] Chun Meiwu. A Brief Study on Web Application Technology in Autonomous[J]. Learning of Learners. 2014, 2920:523-526.

[3] Wang Tingting, Yi Mengchun, Chen Xin. The Use of Critical Thinking of College Students in Network Situations-Taking Xiamen University as an Example[J]. Journal of Changsha University,2015,29(3):129-131.

[4] Shi Huihua. The Lack of Independent Thinking Ability and Countermeasures - Based on the Thinking of College Students in Social Science[J].The Science Education Article Collects, 2019(1):50-51+60

[5] Hou Dongcheng, Xu Jianwen. Analysis of the change of college students' thinking mode in the network environment. [J] Journal of Southwest Minzu University(Humanities and Social Science), 2001(08):191-194+237.
[6] Huang Shanyya, Chen Lei. Analysis of the influence of college students' thinking in the network environment. [J] Modern Science,2009(12):294.

[7] YAO JianJian.The evolution of information network and man's cognitive model[J].Xinjiang Social Sciences,2003(1):13-16.

[8] Li ZhiHong.The transformation of network and people's thinking mode[J].Jiangxi Social Sciences,2004(3):22-25.

[9] Chang Jinfang. The mode of internet thinking — the fifth great revolution of the human beings' mode of thinking, Theoretical learning,2002(1):46- 48 .

[10] Zhou Kewu.The transformation of the mode of thinking in the network age[J].Qinghai Social Sciences, 2003(2):54-56. 